\title{
DISPUTAS TERRITORIALES Y RESIGNIFICACIÓN COLECTIVA DEL HÁBITAT. NOTAS EN TORNO A LA PRODUCCIÓN DE LO COMÚN DESDE EL CASO DE PARQUE ESPERANZA, CÓRDOBA, ARGENTINA
}

Disputas territoriais e resignificação coletiva do habitat Notas sobre a produção do comum do caso do Parque Esperanza, Córdoba, Argentina

Territorial disputes and the collective resignification of the habitat. Notes on the production of the common from the case of Parque Esperanza, Cordoba, Argentina

\section{Ana Laura Elorza}

Investigadora Asistente CONICET, INVIHAB, FAUD. Dra. en Ciencias Sociales. Docente de Facultad de Ciencias Sociales. Consejo Nacional de Investigaciones Científicas y Técnica (CONICET). Instituto de Investigación de la Vivienda y Hábitat. Universidad Nacional de Córdoba. Córdoba. Argentina.

analauraelorza@hotmail.com

https://orcid.org/0000-0001-7099-6307

\section{Denise Mattioli}

Investigadora Asistente CONICET, INVIHAB, FAUD. Dra. en Arquitectura. Docente. Consejo Nacional de Investigaciones Científicas y Técnica (CONICET). Instituto de Investigación de la Vivienda y Hábitat. Universidad Provincial de Córdoba. Córdoba. Argentina. den.mattioli@gmail.com https://orcid.org/0000-0003-1315-7288

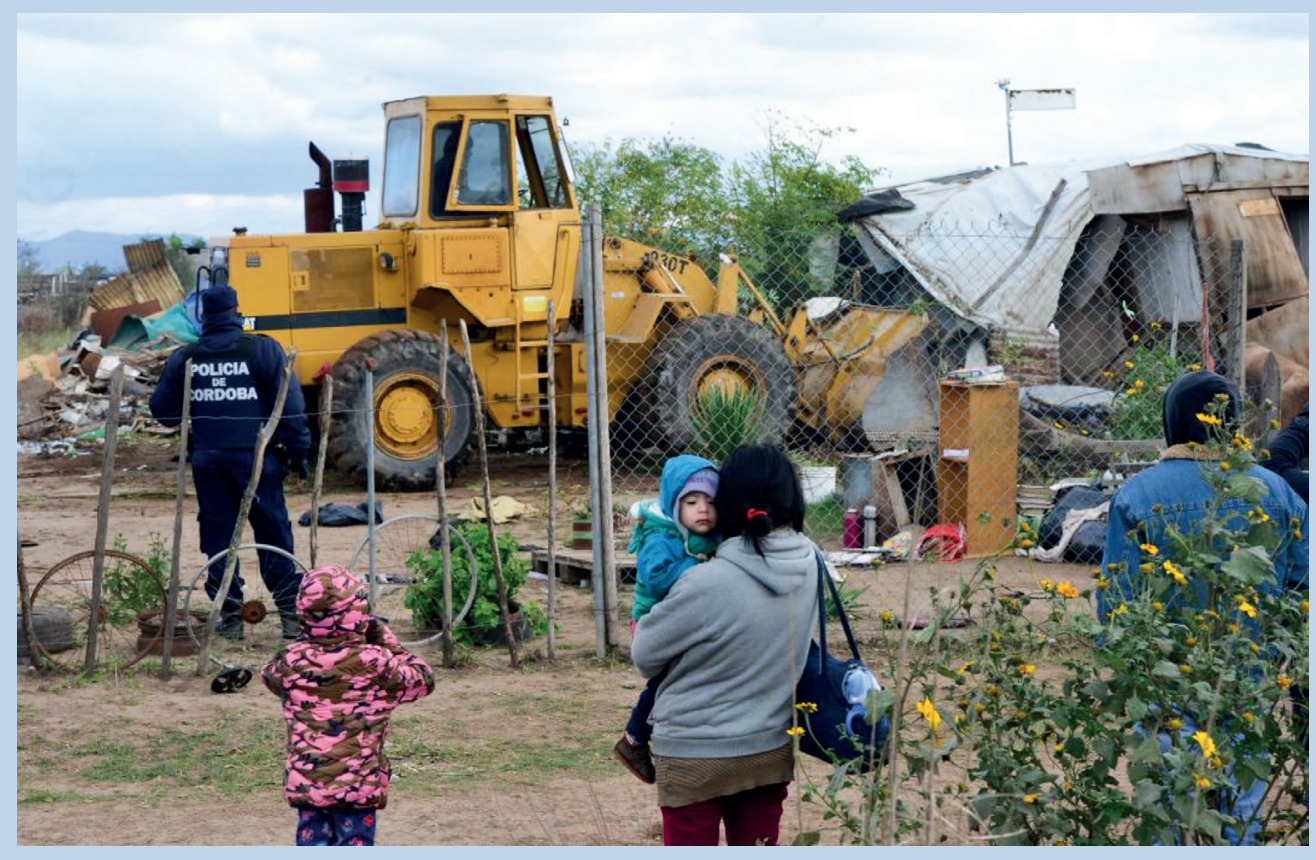

Este artículo cuenta con el financiamiento de la Secretaría de Extensión de la Universidad Nacional de Córdoba, además se agradece a las personas de la comunidad de Parque Esperanza por permitirnos acompañar su proceso de lucha por la efectivización de los derechos a la tierra y vivienda. 


\section{RESUMEN}

Las ciudades actuales se caracterizan por atravesar un proceso de profundización de las desigualdades socioterritoriales en función del avance de la materialización espacial de los capitales financieros y la apropiación de los territorios urbanos como estrategia de rentabilidad. Sin embargo, colectivos sociales diversos disputan los espacios que el capital captura mediante estrategias colectivas de resistencia y visibilización de sus problemáticas, poniendo en relevancia la dimensión de "lo común", dado el ejercicio sentidos de base colectiva, colaborativa o comunitaria. Este artículo tiene como objetivo analizar e interpretar las resistencias de los pobladores que han producido socialmente sus territorios desde lo común frente a las estrategias de expulsión derivadas de procesos especulativos de la tierra y negocio inmobiliario, en el marco de las particularidades que asume este proceso de desposesión en la región metropolitana de Córdoba (Argentina). Particularmente, presentamos un análisis sobre el caso de Barrio Parque Esperanza, que frente a en un proceso de desalojo judicial de su territorio barrial en el año 2018, ha resistido durante 14 meses en un proceso de resistencia colectiva y negociación con el estado provincial hacia la efectivización del derecho a la tierra y vivienda. El acercamiento epistemológico recupera la idea del diálogo de saberes propuesto por las epistemologías del sur y decoloniales, pues interesa recuperar las experiencias desde la perspectiva de los actores en sus propios territorios, en busca de aportar conocimientos para evidenciar una situación específica de la realidad social caracterizada por procesos de fragilidad y a la vez, potencialidad para abonar a la producción del hábitat desde lo común.

Palabras Clave: Territorio, desigualdades sociales, conflicto social, hábitat, organización social

\section{RESUMO}

As cidades de hoje são caracterizadas por atravessar um processo de aprofundamento das desigualdades sócio-territoriais em função do avanço da materialização espacial do capital financeiro e da apropriação de territórios urbanos como estratégia de rentabilidade. Entretanto, diversos grupos sociais disputam os espaços que o capital captura por meio de estratégias coletivas de resistência e visibilidade de seas problemáticas, destacando a dimensão do "comum", dado o exercício de sentidos coletivos, colaborativos e / ou comunitários. O objetivo deste artigo é analisar e interpretar a resistência dos moradores que produziram socialmente seus territórios a partir do comum diante de estratégias de expulsão derivadas de processos especulativos de negócios imobiliários, no quadro das particularidades que assume este processo desapropriação na região metropolitana de Córdoba (Argentina). Em particular, apresentamos uma análise sobre o caso do Barrio Parque Esperanza, que frente a um processo de despejo judicial em 2018, resistiu por 14 meses em um processo de resistência coletiva e negociação com o governo regional em direção à efetivação do direito à terra e moradia. A abordagem epistemológica resgata a ideia do diálogo de saberes proposto pelas epistemologias do Sul e descoloniais, pois interessa recuperar as experiências da perspectiva dos atores em seus próprios territórios, em busca de fornecer conhecimento para evidenciar uma situação específica da realidade social caracterizada por processos de fragilidade e, ao mesmo tempo, potencialidade para fertilizar a produção do habitat a partir do comum. Palavras Chave:Território, desigualdade social, conflito social, habitat, organização social

\section{ABSTRACT}

Cities today are going through a process that deepens socio-territorial inequalities based on the advance of the spatial materialization of financial capitals and the appropriation of urban territories as a profitability strategy. However, diverse social groups dispute the spaces that this capital captures through collective strategies of resistance and by raising awareness, highlighting the dimension of "the common", giving the exercise of the collective, the collaborative and/or community-based senses. This article aims at analyzing and interpreting the resistance of the residents who have socially produced their territories from the common in the face of expulsion strategies derived from speculative real estate processes, within the framework of the particularities assumed by this dispossession process in the metropolitan region of Córdoba (Argentina). In particular, we present the analysis of the Barrio Parque Esperanza case, which when faced with a process of judicial eviction from its neighborhood in 2018, has stood its ground for 14 months in a process of collective resistance and negotiation with the provincial state towards making the right to land and housing effective. The epistemological approach recovers the idea of the dialogue of knowledge proposed by the southern and decolonial epistemologies, since it seeks to recover the experiences from the perspective of the players in their own territories, looking to contribute with knowledge to demonstrate a specific social reality situation characterized by processes of fragility and, at the same time, with potential to boost the production of the habitat from the common.

Keywords: Territory, social inequality, social conflict, habitat, social organization 


\section{INTRODUCCIÓN}

Las ciudades se han caracterizado desde sus orígenes por ser espacios atravesados por conflictividades relacionadas con el poder, ya que se trata de concentraciones geográficas y sociales de un producto excedente socialmente definido, el que es apropiado por un grupo minoritario en detrimento de las mayorías (Harvey, 1977, Signorelli, 1999). Lejos de menguar dicha condición asimétrica en torno a los aglomerados urbanos, en las últimas décadas los conflictos en torno al acceso, uso y apropiación de la ciudad se hacen más evidentes a partir del "boom inmobiliario". Al respecto, Harvey (2009) sostiene que grandes flujos de capital son invertidos en el mercado de vivienda y proyectos de infraestructura, lo que ha tenido como consecuencia procesos de "acumulación por desposesión" que ha generado numerosos conflictos relacionados con la captura de suelo valioso, ocupado por años por poblaciones de bajos ingresos que en la mayoría de los casos termina con su expulsión hacia sectores de mayor vulnerabilidad.

En este contexto de disputa desigual por la apropiación del espacio urbano, Rolnik (20 I 8) plantea que las estrategias de acumulación de inicios de Siglo XXI, están relacionadas con la vertiente financiera que ha adquirido la economía y la política, cuya materialización espacial se verifica a través de la producción de "paisajes para la renta", a partir de la configuración de novedosos procesos de resignificación de los territorios urbanos desde una lógica de extractivismo urbano (Svampa y Viale, 2014; Vásquez Duplat, 2017). Dicha lógica genera fricciones y disputas con los "paisajes para la vida", el primero como negocio inmobiliario y el segundo, como lugar para la reproducción de la vida cotidiana.

Los nuevos "paisajes para la renta" en las ciudades de América Latina, son implantados en sectores específicos de las mismas, identificados como espacios de residencia y consumo para las élites y sectores medios (por ejemplo, centros comerciales, tiendas y servicios "de diseño", conjuntos cerrados en altura, countries, etc.) que en muchas oportunidades rompen tejidos históricos o socioculturalmente apropiados y reconocidos por sus habitantes y pasan a ser nuevas fronteras, en relación a los "paisajes para la vida", muchos de los cuales son construidos desde la lógica de la supervivencia, de las necesidades materiales y los deseos de prosperidad, producidos con escasos recursos y en terrenos disponibles (periferias, áreas en riesgo ambiental, etc.) (Rolnik, 2018). Claramente esta disputa y conflicto por la apropiación del territorio es desigual, y no solo se expresa como fronteras materiales y simbólicas, sino también a través de estrategias de expulsión de los pobladores clasificados como informales o ilegales, a partir del engranaje económico, político y judicial que lo facilita.

Estos procesos de acumulación por desposesión o expulsión de sectores populares en ciudades de la región han sido abordados en el campo de estudios urbanos desde diferentes abordajes. Algunos se han centrado en los procesos de transformación territorial y gentrificación de ciertas áreas de la ciudad (por la renovación del centro histórico, revitalización de ciertos barrios tugurizados, nuevos grandes 
1 Por ejemplo, en las comunidades Comechingones en Cuesta Blanca, Villa La Maternidad, Nuestro Hogar III, entre otros. proyectos urbanos, etc.) y las consecuencias que tuvieron para sus pobladores, siendo expulsados por la presión inmobiliaria y el aumento de los costos de la residencia (Janoschka, 20 16; Salinas, 20 17; Vásquez Duplat, 2017, 2018). Otra línea de análisis se refiere a cómo en este contexto de profundización y polarización de las desigualdades, colectivos sociales diversos disputan los espacios que el capital captura mediante estrategias colectivas de visibilización de sus problemáticas y de resistencia y (Casgrain y Janoschka, 2013; Pérez, y Matus, 20 I7; Elorza y Morillo, 20 17; entre otros). En especial, interesa recuperar el trabajo de Gutiérrez Aguilar, Navarro Trujillo y Linsalata (2016) dedicado al estudio de "Entramados comunitarios y formas de lo político", desde la que abonan a la categoría de "la producción de lo común" a partir del estudio de otras formas posibles de organización y reproducción de la vida social más satisfactorias respecto de los modos de existencia impuestos por el mundo moderno y capitalista, en las experiencias de autonomía de comunidades originarias, populares y urbanas periféricas.

La emergencia de "lo común" se dispone, entonces, como categoría analítica fecunda para explorar los procesos de captura del capital sobre los medios de producción y reproducción de la vida en el contexto de una economía política de financiarización global, específicamente en los procesos de producción social del hábitat de los sectores populares que habitan los márgenes de las grandes ciudades.

No ajeno a este proceso de producción de ciudad, sectores estratégicos de la región metropolitana de Córdoba (Argentina) cristalizan esta coyuntura en torno a la disputa por la apropiación de los territorios en clave renta/vida. Espacios periféricos que hasta hace dos décadas tenían escaso o nulo valor urbanístico, motivo por el cual se constituían como territorios accesibles a los sectores populares (a través de loteos populares, barrios de vivienda social y estrategias de toma de tierra), comienzan a ser resignificados y disputados por las empresas inmobiliarias para producir nuevas urbanizaciones destinadas a sectores de altos ingresos (countries, complejos de torres, oficinas y comercios, etc.).

En paralelo a la ausencia de políticas públicas habitacionales dirigidas a los sectores populares, en los últimos años se desarrolló una serie de conflictos en torno a procesos colectivos de toma de tierra y producción social del hábitat (Elorza y Morillo, 2017), dirimidos en el plano judicial con órdenes de desalojo de diferentes comunidades'. Cabe destacar que estos procesos estuvieron atravesados por diferentes estrategias de lucha y resistencia por parte de los pobladores y organizaciones sociales en defensa de sus territorios.

Por lo mencionado, se procura analizar e interpretar las resistencias de los pobladores que han producido socialmente sus territorios desde "lo común" frente a las estrategias de expulsión, derivadas de procesos especulativos de la tierra y negocio inmobiliario, en el marco de las particularidades que asume este proceso de desposesión en la región metropolitana de Córdoba (Argentina). Particularmente, presentamos 


\section{METODOLOGIA}

2 El análisis y reflexiones de este artículo se inscriben en el proyecto de extensión "Después del desalojo: estrategias socio-organizativas para la efectivización del derecho a la tierra y la vivienda" bajo la dirección de Susana Andrada y co-dirección de Cecilia Marengo, con la participación de docentes e investigadores de la Facultad de Ciencias Sociales (Elorza Ana Laura y Cuella Silvina) y el Instituto de Investigación de la Vivienda y Hábitat (Mattioli, Denise; Brunelli, Alejandro y Alvarado, Mónica), de la Facultad de Arquitectura, Urbanismo y Diseño, de Universidad Nacional de Córdoba.

3 Las entrevistas fueron realizadas en el periodo comprendido entre abril y octubre del año 2019. un análisis sobre el caso del Barrio Parque Esperanza², que frente a un proceso de desalojo judicial de su territorio barrial en el año 2018, caracterizado por un procedimiento violento, ha resistido durante 14 meses en una causa de resistencia colectiva y negociación con el estado provincial hacia la efectivización del derecho a la tierra y vivienda.

Este trabajo es interpretativo con el desarrollo de una estrategia metodológica de tipo cualitativa. El acercamiento epistemológico recupera la idea del diálogo de saberes propuesto por las epistemologías del sur y decoloniales, pues interesa recuperar las experiencias desde la perspectiva de los actores en sus propios territorios, buscando de esta manera arrimar conocimientos que sean de utilidad no sólo para evidenciar una situación específica de la realidad social sino para aportar a su transformación con herramientas de utilidad para las comunidades afectadas.

El abordaje empírico es un análisis de caso, la comunidad de Barrio Parque Esperanza, ya que esta experiencia de producción social del hábitat permite reconocer las tensiones en las lógicas en la producción de la ciudad, visibilizando las desigualdades en las estrategias de control por la apropiación del territorio y también la agencia y capacidad de los sectores populares hacia la construcción de procesos de reproducción de la vida.

La estrategia metodológica desarrollada consistió, por un lado, en el análisis de fuentes secundarias (trabajos académicos, artículos periodísticos) para una aproximación al proceso de producción de este territorio previo a su desalojo. Por otro lado, realizamos un relevamiento y cartografía de la organización y uso del espacio de la capilla, como lugar de residencia en el proceso de posdesalojo y entrevistas semiestructuradas a personas adultas de las familias organizadas colectivamente por la efectivización del derecho a la tierra y vivienda ${ }^{3}$. Este universo se compone de 9 familias que residen en la capilla y otras 15 que han desarrollado otras estrategias habitacionales a la espera de una respuesta efectiva por parte del gobierno de la provincia de Córdoba.

Partimos del supuesto que las experiencias de producción social del hábitat desde sentidos y prácticas del territorio como "común", representa la capacidad de agencia para disputar los medios para la producción y reproducción de la vida en condiciones materiales adecuadas en tanto garantías para la dotación de una vida digna, ante la captura que hace el estado-capital de los territorios en tiempos de financiarización de la economía y la política. A tal fin, recuperamos las ideas de "producción de lo común" (Gutiérrez Aguilar, 2016, 2017), "luchas por lo común o hacer común" (Navarro Trujillo, 20 I5) con el fin de desmontar la concepción dual, binaria y jerárquica que la modernidad capitalista y patriarcal atribuye a las esferas de la vida cotidiana, siendo los procesos de producción social del hábitat popular las fronteras que evitan la captura total por parte de las finanzas en las ciudades. En ese sentido, las entrevistas apuntaron a recuperar los sentidos en torno a la construcción del hábitat desde lo común, a los fines de nutrir dicha dimensión de análisis desde la experiencia específica del caso. 


\section{RESULTADOS}

El origen de la comunidad de Parque Esperanza se inicia aproximadamente en el año 2014 con la toma de un terreno que se encontraba ocioso, colindante de un barrio de vivienda social denominado Barrio Ciudad de los Niños, localizado en la municipalidad de Juárez Celman del Área Metropolitana de Córdoba, por parte de familias que provenían de diferentes barrios de la ciudad de Córdoba. En ese momento, la mayoría de esas familias se encontraban alquilando viviendas o cuartos, co-residían con otros hogares o eran mujeres que salían de situaciones de violencia de género y no tenían una vivienda donde alojarse con sus hijos, por lo que participar de la toma de tierra les significaba la posibilidad de acceder a un lote propio para construirse no sólo una solución habitacional sino alejarse de situaciones de violencia.

El proceso de producción social del hábitat fue rico en tanto trabajo colectivo de construcción de un lugar para vivir desde la base del trabajo familiar y comunitario, en un terreno "descampado" y sin servicios. Las unidades habitacionales fueron autoproducidas con madera y nailon y algunas pocas de material. Colectivamente, se construyó un espacio comunitario donde realizaban diferentes acciones para promover un espacio de encuentro, de organización y solidaridad (copa de leche, almuerzos comunitarios, y festivales) y se conformó una cooperativa de vivienda (denominada 12 de junio), como estrategia de formalizar y consolidar la organización con horizonte de gestionar un proyecto habitacional.

Cabe destacar que el trabajo realizado estuvo atravesado por disputas por la apropiación del territorio, ya que un sector de los terrenos ocupados es de propiedad de una empresa constructora Urbanor S.A. que tenía proyectado allí la construcción de un barrio cerrado y otro sector pertenece al Gobierno de la Provincia de Córdoba. Este conflicto fue judicializado, lo cual representó sucesivas presiones de desalojo. Además, los pobladores denunciaron que durante los cuatro años de habitar el territorio sufrieron sostenidas amenazas y acciones represivas, por ejemplo, personas externas al barrio les apedreaban sus viviendas e incluso una fue incendiada, o tenían control policial durante todo el día.

Después de varios años de negociaciones frustradas, frente a la demanda de la expropiación de los terrenos por parte de los pobladores y la organización social, el día primero de junio de 2018 se efectiviza el desalojo de la comunidad ( 148 familias) por parte de un operativo con polić́as, a través de un procedimiento con alto nivel de violencia y vulneración de los derechos humanos. Las edificaciones fueron arrasadas con topadoras, y solo algunas familias pudieron recuperar el mobiliario (muebles, ropa, documentación, etc.).

Como respuesta a la situación de vulnerabilidad de estas familias, desde el gobierno provincial se propuso un abordaje de carácter individualista, con un magro subsidio para que pudieran resolver su situación habitacional; algunas familias lo aceptaron, aun reconociendo las limitaciones de la propuesta. Otras, un grupo de aproximadamente 44 familias, como estrategia de resistencia ante el avasallamiento de los derechos humanos, ocuparon esa misma tarde el edificio de una capilla cristiana ubicada en el 


\section{HABITAR LA CAPILLA: ESPACIO DE TRINCHERA Y RESIGNIFICACIÓN ESPACIAL DEL CONFLICTO}

barrio aledaño, Barrio Parque Norte. Esta acción derivó de las dificultades para recurrir a alguna estrategia habitacional en los términos planteados por el gobierno, pero también como una forma de continuar las negociaciones de manera colectiva hacia una respuesta habitacional definitiva que integrara a todas las familias, desde una perspectiva comunitaria.

En agosto de 2019 se firmó un acuerdo con el gobierno provincial por la adjudicación de 33 lotes en barrio San Javier, en un terreno que aún no estaba urbanizado (sin servicios, apertura de calles, subdivisión de lotes), por lo que la posesión de los mismos sería en un año. Para sostener el proceso de resistencia, algunas familias decidieron continuar habitando la capilla.

Como mencionamos, el predio de la capilla se encuentra ubicado en las inmediaciones del terreno en el que estaban haciendo posesión y fueron desalojados. En un primer momento, 44 familias decidieron resistir en dicho espacio. Sin embargo, a pesar de los esfuerzos por sostener a toda la comunidad unida en la lucha, con el transcurso del tiempo, el número de familias en la capilla fue disminuyendo, y ello estuvo asociado a las dificultades que el espacio habitacional imponía a la resolución de necesidades básicas; y también a la pérdida de expectativas en relación a una respuesta sobre la entrega de los lotes por parte del gobierno, ya que no se vislumbraban avances concretos sobre la adjudicación de los lotes. Cabe destacar que la producción y reproducción cotidiana de estas familias se dificultó aún más, en el marco de la coyuntura de crisis económica del país y también a raíz de la suspensión de las donaciones de alimentos que recibían, que representaban un importante aporte para garantizar la alimentación diaria.

Algunas familias desarrollaron diversas estrategias habitacionales, como la co-residencia con otros hogares (muchas de ellas ubicadas también en asentamientos o barrios de sectores populares, alquilaron habitaciones, o casillas de madera; etc.) a través de las cuales han accedido a un lugar de residencia, aunque sin estar exentas de precariedad habitacional (situaciones de hacinamiento y condiciones sanitarias deficientes), tensiones y conflictos derivados de la prolongación del tiempo de permanencia en un espacio reducido.

Un grupo de nueve familias (29 personas en total) continuaron con su residencia en la capilla y desarrollaron diferentes estrategias de organización del espacio para poder habitar dicho edificio. Si bien el mismo se encuentra en buen estado y cuenta con provisión de servicios básicos, la función por la cual fue creado (culto religioso) no es compatible con la función de habitar, menos aún para una cantidad significativa de personas que tuvieron que adaptarse, no sólo a las condiciones reducidas y atípicas del espacio, sino a compartir la cotidianeidad, viendo afectada su privacidad y dinámicas familiares. En este sentido, la estrategia desarrollada consistió en establecer espacios diferenciados para cada hogar, dividiendo el espacio interior de la capilla para cinco familias y las cuatro restantes se dispusieron en el espacio libre circundante, en unidades/casillas. 
Al interior de la capilla, las subdivisiones se realizaron con paneles de madera de $2 \mathrm{~m}$ de altura, resultando en unidades habitacionales mínimas con superficies de entre 15 y $20 \mathrm{~m}^{2}$ aproximadamente, lo que derivó indefectiblemente en situaciones de hacinamiento crítico, falta de asoleamiento y ventilación adecuada. Asimismo, cabe destacar, que estos reducidos espacios son utilizados no solo para descansar (dormir) sino también cocinar, comer, bañarse, etc.

Los módulos habitacionales organizados en el exterior se desarrollaron por vía seca, con paneles laterales de madera y techos de chapa o madera, recubiertos con lonas y nailon como barrera para la aislación. Es decir, ninguna de estas unidades cuenta con aislaciones térmicas efectivas y condiciones de seguridad ante eventualidades climáticas (fuertes lluvias, granizos, vientos). Por otra parte, en relación a las superficies de estos módulos, están conformados por un único espacio de aproximadamente $20 \mathrm{~m}^{2}$, por lo que también se registran situaciones de hacinamiento.

Desde esta condición, se desprende que las características habitacionales tanto de quienes habitan al interior de la capilla como quienes lo hacen afuera son de profunda precariedad [Figura Iy 2]. Mediante un

Figura 1

Espacio de la

capilla habitado

por las familias.

Fuente: Denise

Mattioli (2019).

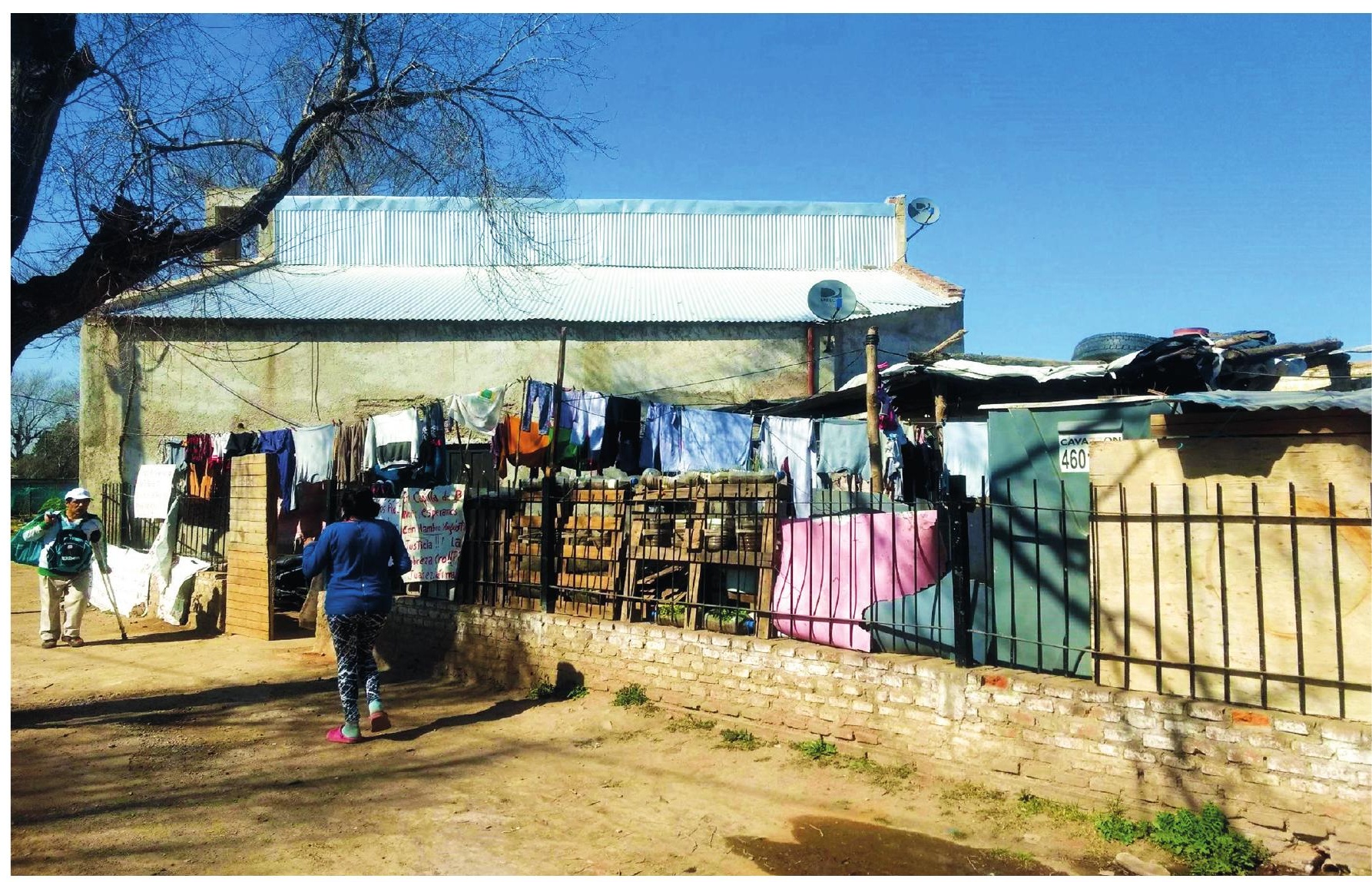

AS / Vol. 38. No58 / JULIO 2020 // ISSN impresa 071 6-2677 / ISSN digital 0719-6466 


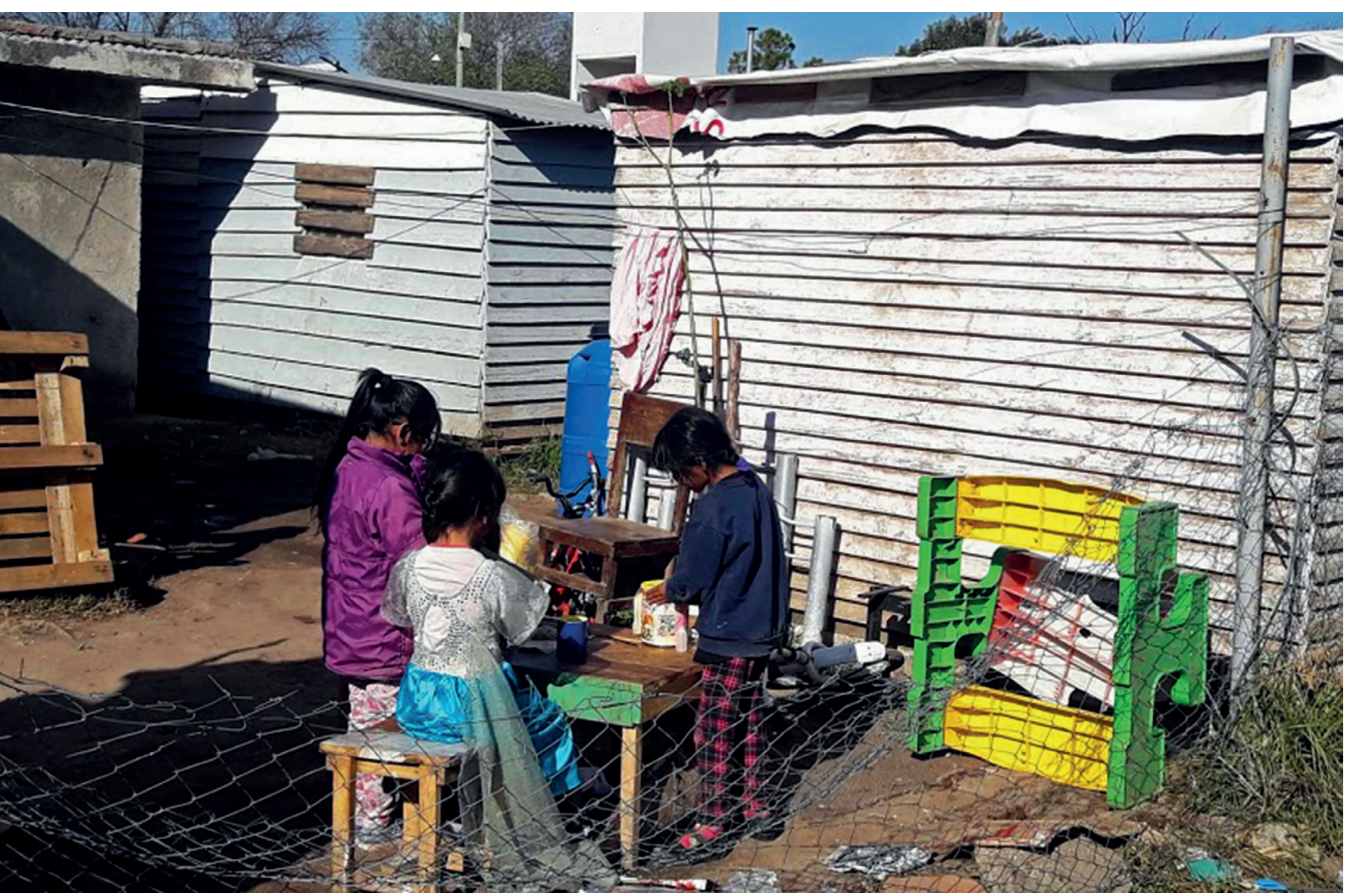

Figura 2

Espacio de la

capilla habitado

por las familias

Fuente: Denise

Mattioli (2019)

relevamiento de las características del edificio, se ha verificado que el recinto no posee un acondicionamiento térmico y acústico acorde a requisitos habitacionales (por ejemplo, la falta de aislación en los techos de chapa genera situaciones de frío o calor intensos, representando situaciones de riesgo para la salud de las personas que allí residen). El sistema eléctrico al interior de la capilla es deficiente e insuficiente para la gran demanda, lo cual configura otra situación de inseguridad, habiéndose registrado un incendio en el tablero eléctrico debido a la sobrecarga de la instalación original por el aumento del consumo.

Además, el edificio cuenta con un solo baño, que al poco tiempo colapsó la instalación cloacal, quedando inutilizado. A ello se le suma que el agua disponible para consumo humano se encuentra sucia dado la falta de mantenimiento del tanque, según los testimonios de los entrevistados. En respuesta a las demandas por la situación sanitaria crítica de estas familias, el gobierno provincial instaló ocho baños químicos en el predio, que son compartidos entre todas las personas. Cabe destacar que el drenaje de estos baños se realiza semanalmente, generando si- 


\section{NOCIONES Y SENTIDOS SOBRE LA PRODUCCIÓN DE LO COMÚN}

AS / Vol. 38. No58 / JULIO 2020 // ISSN impresa 07 I 6-2677 / ISSN digital 0719-6466 
necesidad de tener un lugar concreto donde vivir y que sea propio..."; "teníamos una pieza de material y la cocina, comedor y baño de tarimas y cartón prensado. Demolieron y sacamos la ropa, el frezar, las camas... Perdimos todo. Estábamos esperanzados de quedarnos ahî'; "cuando fui a conocer el barrio me enamoré, era muy tranquilo, pude levantar una pieza e instalar un kiosco, que era mi fuente de trabajo y de ingresos, con el desalojo perdí todo...".

Recuperando la dimensión colectiva del proceso de producción del hábitat, desde una noción integral del territorio no solo como lugar de residencia, a más de un año de haber sufrido el desalojo y la pérdida de su lugar para la vida, se aprecia un fuerte arraigo hacia la experiencia de comunización vivida, "teníamos los sábados jornadas comunitarias en las que compartíamos almuerzos, charlábamos y pensábamos cómo mejorar el barrio, construimos el salón comunitario entre todos"; "pasamos momentos muy duros todos juntos, cuando decían que nos iban a desalojar y organizábamos acciones para que toda la sociedad conociera nuestra lucha".

Estas valoraciones dan cuenta de vínculos de confianza, apoyo y ayuda mutua que posibilitan la reciprocidad social, y el sostén colectivo, aún en condiciones de adversidad. Consideramos que estos sentidos son los que fundamentan la persistencia del entramado organizativo actual, generando espacios para la producción de lo común como el espacio de encuentro para las reuniones y asambleas, la huerta comunitaria y en la resistencia actual hacia la efectivización de los derechos de tierra y vivienda.

En este sentido, las expectativas en relación a la resolución de este conflicto que expresa el colectivo de familias, gira en torno al reconocimiento de un trato digno como sujetos de derechos y de las demandas de tierra y vivienda de manera conjunta, que posibilite la re-construcción de la comunidad de Parque Esperanza en un nuevo lugar. Y en esa dirección desarrollan una serie de acciones para vehicularizarlas, como el proyecto de fabricación de ladrillos ecológicos realizado por un grupo de mujeres para construir la nueva sede comunitaria y las gestiones en los diferentes organismos públicos.

En sintonía con el contexto de globalización, el control de la producción de la ciudad por parte de las finanzas globales y la creciente participación de la figura del financiero en los desarrollos inmobiliarios refuerza la concepción binaria y jerárquica de las mismas. Los paisajes para la renta y los paisajes para la vida, de los que habla Rolnik (20 l 8) emergen como resultados de un tratamiento fragmentario y asimétrico de la realidad social. Siguiendo a las epistemologías del sur y decoloniales, esta fragmentación se remite a la ontología de la racionalidad moderna, que cristalizó a lo largo de 500 años la colonialidad de poder, del saber y del ser (Quijano, 2000; Lander, 2000; Souza, 2009; Maldonado-Torres, 2007) desde la instalación del régimen colonial con las leyes de indias y 
4 Sousa Santos (2016) recupera la perspectiva dual y fragmentada de la realidad social cuando reflexiona sobre las ciudades de la contemporaneidad, ciudades en las que conviven dos ciudades, la metropolitana (la que tiene garantizado el derecho a la ciudad) y la colonial (la de los condenados a la ciudad, es decir, la ciudad de los excluidos). Entre ambas se extiende una "línea abismal" que no es física sino simbólica, y está representada por los modos de dominación modernos: el capitalismo, el colonialismo y el patriarcado, los que operan de manera conjunta y articulada. que se reactualiza en la actualidad, en la planificación urbano-territorial con la división de funciones, los grandes proyectos urbanísticos y obras de infraestructura, fracturando el territorio y sus comunidades.

En este marco, la concepción dual de las ciudades (centro/periferia; privado/público; cerrado/abierto; ciudad/campo; etc.) responde a un diseño particular del mundo moderno que legitima el orden capitalista y patriarcal, al poner al individuo y al capital por delante de lo colectivo y lo común (bienes naturales comunes como los recursos naturales, espacios e instituciones públicas). En ese sentido, la distinción que hace Rolnik (20 I 8) sobre la consolidación de los paisajes para la renta en detrimento de los paisajes para la vida, puede ser entendido bajo esta lógica de la separación: la primera asociado a la ciudad formal (de las elites blancas, de los colonizadores y del sector criollo que se alía con las elites) y la segunda con la ciudad informal (de los sectores populares, autoproducidas en las periferias), en una clara relación asimétrica de poder, ya que el primer elemento del binomio es el que tiene el poder de enunciación y el segundo es subsidiario o subordinado a los dictámenes del primero4.

A los paisajes para la vida, Rolnik (2018) les atribuye un carácter de transitoriedad, pues son espacios latentes para ser capturados por los paisajes para la renta hacia la expansión del capital financiero y aclara "ahí se desaloja, se desplaza y vemos los megaproyectos, megadesalojos masivos de todo tipo de vínculo y tenencia de tierra que no es la propiedad individual registrada" (p. 244).

La mercantilización de la naturaleza a lo largo de la historia consolidó la desposesión de los medios para la producción y reproducción de la vida; en los procesos de extractivismo contemporáneos también se re-actualizan los principios coloniales de apropiación de los territorios, en términos de supremacía de la propiedad privada frente a la posesión, como elemento esencial para la reproducción de la vida de los sectores populares. Así, la ausencia de títulos dominiales de los territorios de los sectores populares es central en la disputa por el control y apropiación de los mismos, y las expulsiones que se registran en las periferias de la ciudad refuerzan el carácter extractivista de los procesos de producción y acumulación de capital inmobiliario en sectores que antes no eran disputados.

La emergencia de la (in)justicia socio-espacial en las ciudades, las que por mucho tiempo fueron asumidas, naturalizadas y vividas de manera jerárquica, fragmentaria y sexista, hoy se debate en torno al paradigma de los comunes y lo comunal. Ello se debe a que, en la mayoría de los casos, las relaciones sociales que producen común suelen emerger a partir del trabajo concreto y cooperativo de colectividades humanas auto-organizadas que tejen estrategias articuladas de colaboración para enfrentar problemas y necesidades comunes y garantizar así la reproducción y el cuidado del sustento material (Gutiérrez Aguilar, Navarro Trujillo y Linsalata, 2016).

Los movimientos sociales en el espacio urbano dan cuenta de las disputas por la tierra, la vivienda y la ciudad- sus calles, sus barrios, espacios públicos, monumentos e instituciones- interpelando el imagi- 
nario colectivo para re-pensar formas del acceso, usos, apropiación y disfrute de las mismas. Ante esta problemática, el urbanismo feminista (Muxi, et al., 20 I I; Perales, 20 I 4) reclama recuperar la ciudad como un espacio para la convivencia, la relacionalidad ante una ciudad que no es neutral, sino un espacio de tensión en el que se disputan poderes bien definidos que reproducen las asimetrías de género, clase, raza, nivel educativo, cultural, etc.

La producción de lo común, podríamos inferir que también genera una especie de "arraigo" como mencionamos más arriba con la idea de "lo propio". Esta forma de "arraigo", dice Rolnik (20 I 8), es fundamental en términos de afirmación de presencia, derechos y disputa de sentidos y recursos por parte de los sectores populares, que sostienen "el conflicto permanente en la ciudad, en la disputa por el suelo urbano y la ciudad para la vida con respecto al suelo urbano y la ciudad para el capital, para las ganancias"' (p. 249).

Para el caso que estamos analizando, la resignificación de la presencia se materializa no sólo re-creando la comunidad en otro espacio físico-la capilla- sino también, con medidas gráficas como pancartas, carteles y movilizaciones periódicas al centro de la ciudad para evitar que el conflicto pierda resonancia pública y se diluya sin resoluciones por parte del Estado [Figura 3, 4 y 5].

Anclando con lo anterior, Navarro Trujillo (2015) utiliza la idea de fragilidad para describir diversas experiencias colectivas en contextos urbanos que han venido emergiendo en los últimos tiempos para resistir al despojo capitalista y recrear una forma comunitaria de autodeterminación social para garantizar la reproducción de la vida. La dimensión política, en ese sentido, es un factor de relevancia en los procesos socio-organizativos populares y está dado por lo que se tracciona como común -el acceso la tierra- y en común -colectivamente-. Así, un componente muy importante en la dimensión de lo político de estas experiencias, como capacidad de darle forma a la socialidad, es la producción de decisión y determinación colectiva, lo que incluye la puesta en marcha y experimentación de modos organizativos, métodos, procedimientos y maneras en las que se organiza el hacer común, se delibera y se toma una resolución.

La historia del barrio Parque Esperanza y su producción desde procesos colectivos representan formas y modos de construcción del hábitat desde lo común, donde se ponen en diálogo sentidos y estrategias para el sostenimiento de prácticas hacia la reproducción de la vida en términos materiales, simbólicos y políticos. Proceso caracterizado por la fragilidad ante las asimetrías de poder, pero que su re- configuración fue posible posdesalojo, a través de la estrategia de habitar la capilla, como medida de resistencia colectiva hasta efectivizar la resolución del conflicto. Esto significa que el hacer común se organizó para la satisfacción de una necesidad que es tanto individual y colectiva, o sea, compartida por el colectivo social organizado.

La resolución colectiva de habitar transitoriamente en la capilla significó
Figura 3 Exterior de la capilla en $\mathrm{B}^{\circ}$ Parque Norte de la ciudad de Juárez Celman. Fuente: Denise Mattioli (2019)
Figura 4 Casillas de madera ubicadas en el área disponible del predio de la capilla. Fuente: Denise Mattioli (2019) 

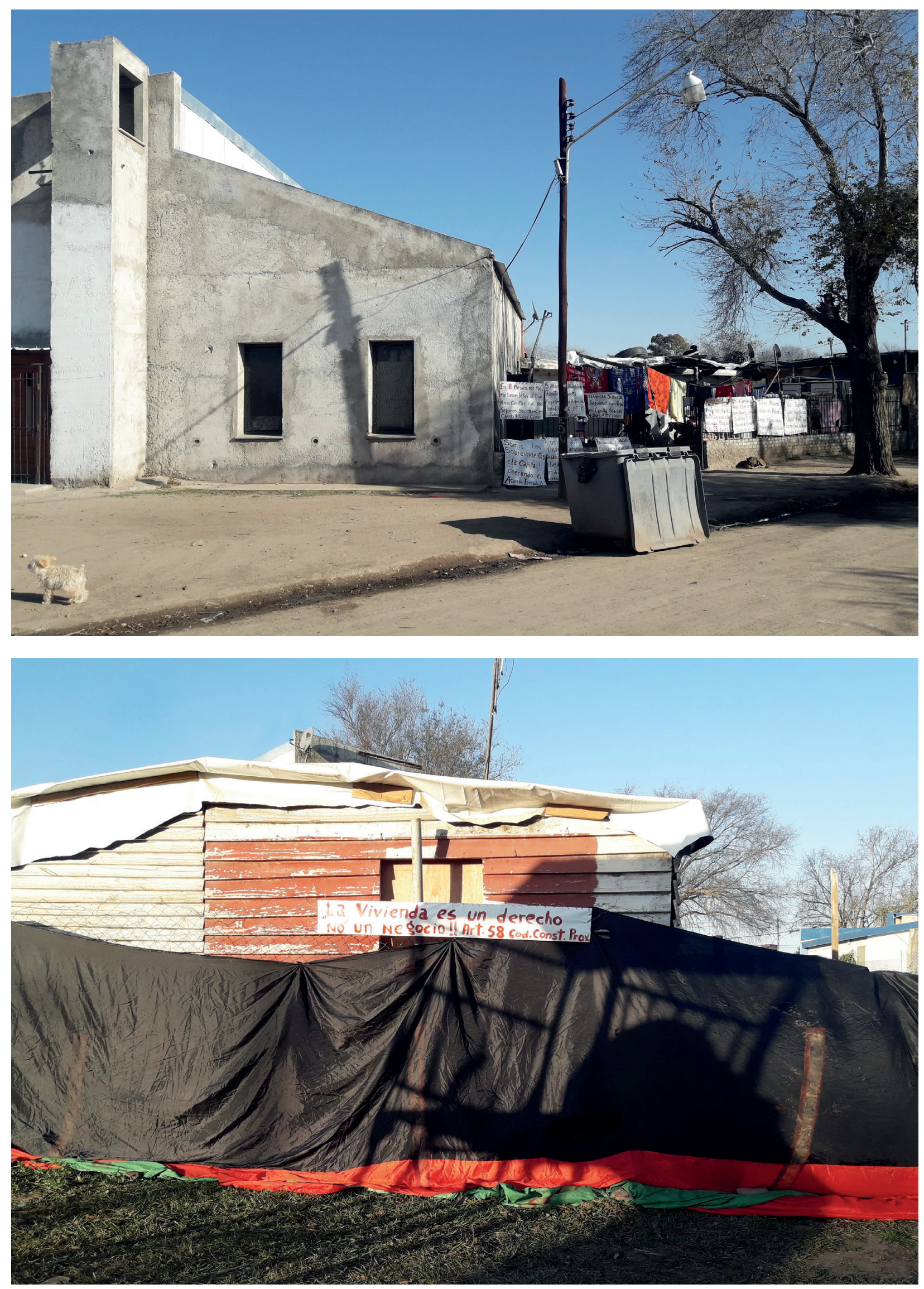

AS / Vol. 38. No58 / JULIO 2020 // ISSN impresa 071 6-2677 / ISSN digital 0719-6466

DISPUTAS TERRITORIALES Y RESIGNIFICACION COLECTIVA DEL HABITAT. NOTAS EN TORNO A LA 


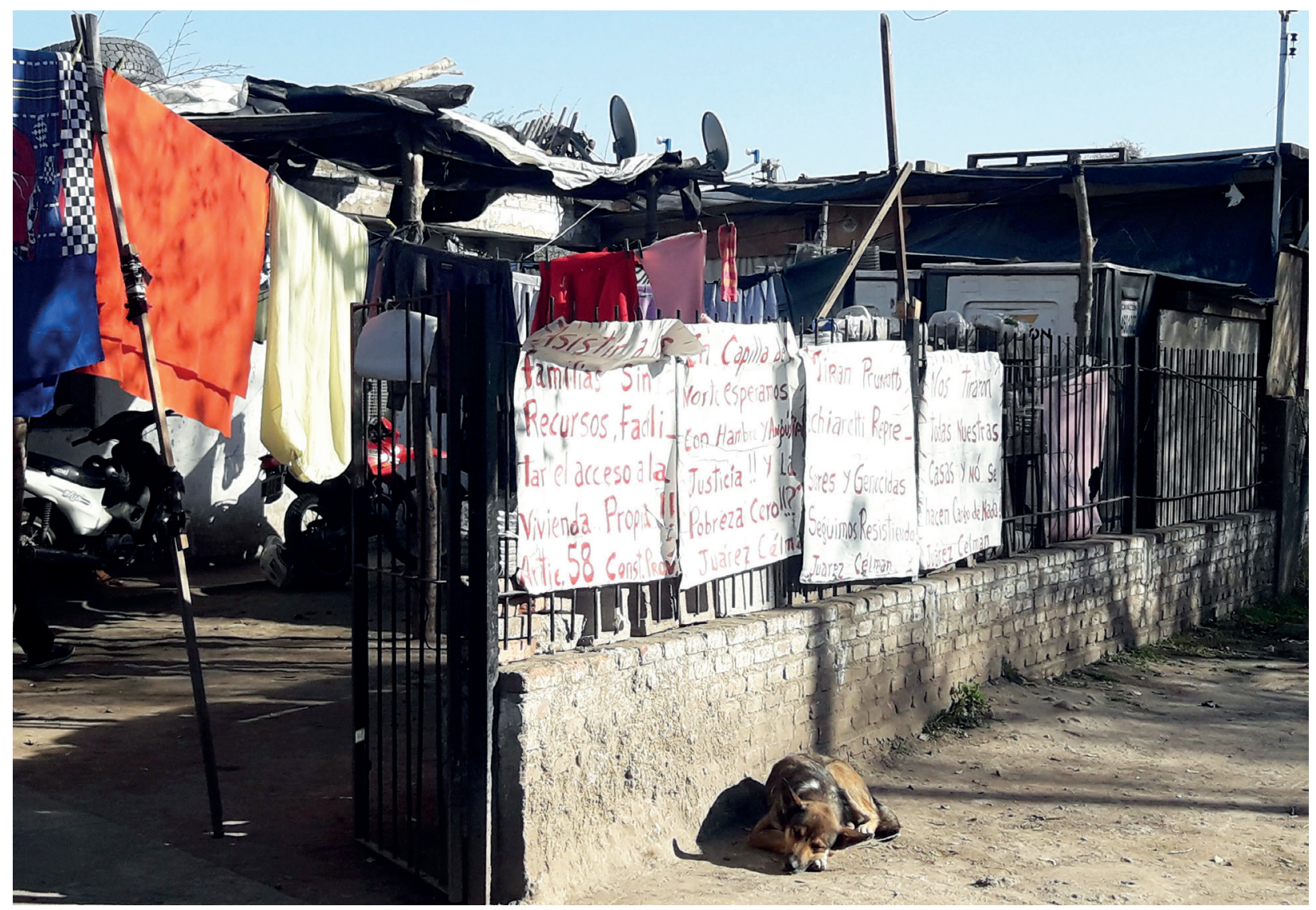

Figura 5

Reapropiación del

espacio común de la

capilla.

Fuente: Denise

Mattioli (2019)

la resistencia a disolver la organización comunitaria por completo. Recordemos que el dispositivo del subsidio contribuyó a la conflictividad social y colaboró en el resquebrajamiento al interior de la organización colectiva. La lógica binaria del estado-capital actúa debilitando la cohesión social aprovechándose de la vulnerabilidad ante situaciones de extrema carencia, enfrentando al interior de las organizaciones su capacidad de forma y agencia. La capilla como hito material y simbólico, adquirió un espacio central en el conflicto, ya que no solo funcionó como recinto de contención para sobrellevar la cotidianidad, sino que en el transcurso del tiempo se fue re-significando para funcionar como espacio asambleario, de formación y capacitación, de visibilización y demás. La función clásica de una capilla que es de uso esporádico y para congregar fieles, queda atravesada por las disputas por la ciudad y se transforma en casa, en vecindad y en trinchera, resignificando el espacio mismo y abriendo a nuevas significaciones dadas por el contexto particular. Ese paisaje que si bien es austero y por demás atípico, permitió sostener las bases materiales para la producción y reproducción de la vida de las familias ante el abandono del Estado. 


\section{CONCLUSIONES}

La ciudad, hemos visto a lo largo del trabajo, está supeditada íntimamente a los dictámenes del capital, y al tiempo que reproduce una estructura jerárquica, dual, fragmentada y excluyente es disputada por sectores sociales diversos que reivindican formas de producción común. Este proceso lo hemos analizado en términos de Rolnik (2018) como espacios en disputa entre paisajes para la renta y paisajes para la vida, desde el caso de la organización colectiva de la comunidad del Barrio Parque Esperanza en sus orígenes de conformación y tras el violento desalojo que derivó en la reubicación temporal en la capilla.

La experiencia de lucha y resistencia de esta comunidad estuvo atravesada por múltiples tensiones tanto en el plano de las disputas y las relaciones de poder, dando cuenta de la fragilidad de estas experiencias. Pero también la producción del hábitat desde lo común permite incorporar a los análisis sobre la producción social del hábitat la capacidad de forma y agencia de los pobladoras de los territorios urbanos como estrategias colectivas para la reproducción de la vida en términos materiales, simbólicos y políticos, constituyendo el acceso al derecho a la tierra un proceso reivindicativo, a partir del cual las demandas de tierra y vivienda es colectiva. Esa tracción colectiva es la que asegura la re-construcción de toda la comunidad de Parque Esperanza en un nuevo lugar.

En términos epistemológicos, la agenda de debate que estas reivindicaciones sociales ponen en escena es la posibilidad de hacer lecturas socio-espaciales que desanden los caminos binarios y duales que se han instituido como pilares de la realidad social en favor de contemplar la diversidad de formas de ser, estar, producir y significar los territorios y los espacios; cuestiones relacionadas con la idea de lo común. Desde esta arista de la producción de lo común, siguiendo a Rolnik (2018) la idea del derecho a la ciudad esgrimida allá por la década del 60 permite ser repensada nuevamente al calor de los acontecimientos que se vivencian en las ciudades del siglo $X X \mid$ como una "plataforma flotante" de articulación de movimientos tanto sociales como de estado-capital en la que se cristalizan las asimetrías de poder; en cuanto que los movimientos sociales proclaman su uso como espacio de vida y el estado-capital como espacio de control y lucro. La incompatibilidad de estas esferas coloca en el centro la dimensión política de las ciudades, como territorios de conflictos siempre en movimiento y rearticulación, resignificándolas.

Abordar las problemáticas del hábitat popular incorporando marcos teóricos críticos como los que proveen las epistemologías del sur y decoloniales colaboran en reflexionar sobre las asimetrías en clave histórica de dominación colonial, en tanto que ofrecen horizontes para re pensar la realidad social desde la perspectiva de lo común, todo lo cual se traduce en aportes para la descolonización y la despatriarcalización del conocimiento hegemónico sobre las ciudades. 


\section{REFERENCIAS BIBLIOGRÁFICAS}

CASGRAIN, A. y JANOSCHKA, M. (2013). Gentrificación y resistencia en las ciudades latinoamericanas: El ejemplo de Santiago de Chile. Andamios, 10(22), 19-44. Recuperado de: http://www.scielo.org.mx/scielo.php?script=sci_arttext\&pid=S1870-00632013000200003\&lng=es\&tlng=es.

ELORZA, A. L. Y MORILLO, E. (2017). El territorio urbano en disputa: representaciones y prácticas en procesos de autoproducción del hábitat. Revista ConCiencia Social, 1, 1. Recuperado de: https://revistas.unc.edu.ar/index. php/ConCienciaSocial/article/view/18426

Facultad de Ciencias Sociales (2018). Informe barrio comunitario Parque Esperanza - Juarez Celman. Recuperado de: https://sociales.unc.edu.ar/sites/ default/files/Informe\%2OPARQUE\%20ESPERANZA.pdf

GUTIÉRREZ AGUILAR, R. NAVARRO TRUJILLO, M. LINSALATA, L. (2016). Repensar lo político, pensar lo común. Claves para la discusión. En: Inclán, D. Linsalatta, L. y Millán, M. (coords.) Modernidades alternativas. México: Ediciones del lirio UNAM.

GUTIÉRREZ AGUILAR, R. (2017). Horizonte comunitario-popular. Producción de lo común más allá de las políticas estado-céntricas. Madrid, España: Traficantes de sueños.

HARVEY, D. (2009) El derecho a la ciudad. Revista digital del Programa de Gestión de la Ciudad, 1. Barcelona, España: Universitat Oberta de Catalunya. HARVEY, D. (1977). Urbanismo y desigualdad social. Madrid, España: Siglo XXI.

JANOSCHKA, M. (2016) Gentrificación, desplazamiento, desposesión: procesos urbanos claves en América Latina. Revistainvi 31 (88): 27-71. Recuperado de: http://revistainvi.uchile.cl/index.php/INVI/article/view/1087

LANDER, E. (2000). Ciencias sociales: saberes coloniales y eurocéntrico. En LANDER, E. (ed.), La Colonialidad del saber: Eurocentrismo y Ciencias Sociales. Perspectivas Latinoamericanas. Buenos Aires, Argentina: CLACSO.

MALDONADO-TORRES, N. (2007). Sobre la colonialidad del ser: contribuciones al desarrollo de un concepto. En: Castro-Gómez, S. y Grosfoguel, R. (eds.) El giro decolonial. Reflexiones para una diversidad epistémica más allá del capitalismo global. pp. 127-167. Bogotá, Colombia: lesco-Pensar-Siglo del Hombre Editores.

MUXI, Z., CASANOVAS, R., CIOCOLETTO, A., FONSECA, M., Y GUTIÉRREZ, B. (2011). ¿Qué aporta la perspectiva de género al urbanismo? Revista Feminismo/s, 17, pp. 105-129. Recuperado de: https://punt6.files.wordpress. com/2011/03/z-muxc3ad-martc3adnez-r-casanovas-a-ciocoletto-m-fonseca-y-b-gutic3a9rrez-valdivia.pdf

NAVARRO TRUJILLO, M. (2015). Hacer común contra la fragmentación en la ciudad: experiencias de autonomía para la reproducción de la vida. Revista El Aplante. 1.

PERALES, V. (2014). Ecofeminismo y Ciudad: Mujeres pensando una ciudad más saludable. Revista Arte y Ciudad, 6, pp. 7-26. Recuperado de: https:// www.researchgate.net/profile/Veronica_Perales_Blanco

PÉREZ, L. Y MATUS, C. (2017). De la resistencia urbana al urbanismo ciudadano: Sujetos y estrategias patrimoniales en Concepción Metropolitano, Chile. Revista de Geografía Norte Grande, (66), 167-192. Recuperado de: https://scielo.conicyt.cl/scielo.php?script=sci_arttext\&pid=S0718-34022017000100010

QUIJANO, A. (2000). Colonialidad del poder, eurocentrismo y América Latina. En: Lander E. (ed.), La Colonialidad del saber: Eurocentrismo y Ciencias Sociales. Perspectivas Latinoamericanas. Buenos Aires, Argentina: Clacso.

ROLNIK, R. (2018). Prólogo. En Hernández Manuel y Díaz García V. (Coord.) 
Visiones del hábitat en América latina. pp. 7-11. Madrid, España: Ed. Reverte.

SALINAS, L. (2017). ¿Gentrificación latinoamericana? Apuntes para su discusión. RevistArquis, 6 (1), pp.1-10. Recuperado de: https://revistas.ucr.ac.cr/ index.php/revistarquis/article/view/29205/29180

SIGNORELLI, A. (1999). Antropología urbana. Barcelona, España: Editorial Antrophos.

SOUSA SANTOS, B. (2016). Desde la perspectiva de los condenados a la ciudad. En: Borja, J. Carrión, F. y Corti, M. (eds.) Ciudades para cambiar la vida. Una crítica a Hábitat III. Buenos Aires, Argentina: Café de las ciudades.

SOUSA SANTOS, B. (2009). Una epistemología del sur. La reivindicación del conocimiento y la emancipación social. México: Siglo XXI. Clacso.

SVAMPA, M. Y VIALE, E. (2014). Maldesarrollo: La Argentina del extractivismo y el despojo. Buenos Aires, Argentina: Katz.

VÁSQUEZ DUPLAT, A. M. (2017). Extractivismo urbano: debates para una construcción colectiva de las ciudades. Buenos Aires, Argentina: Ceapi-Fundación Rosa Luxemburgo.

VÁSQUEZ DUPLAT, A. M. (2018). Desalojos y extractivismo urbano en Argentina. Cuerpos y resistencia feminista. Revista Bravas, 6. Recuperado de: http://viejo.revistabravas.org/article/243/cuerpos-y-resistencia-feminista 